\title{
EFFECT OF THE RADIOLITIC STERILIZATION IN POLYETHYLENE/STARCH BLENDS
}

Flávia Gonçalves Domingues Ferreira, Maria Alice Gomes de Andrade Lima, Yêda Medeiros Bastos de Almeida e Glória Maria Vinhas*

Departamento de Engenharia Química, Universidade Federal de Pernambuco, Av. Prof. Artur de Sá, s/n, 50740-521

Recife - PE, Brasil

Recebido em 20/3/07; aceito em 11/10/07; publicado na web em 2/4/08

\begin{abstract}
Samples of LDPE/modified starch blends $80 / 20 \mathrm{~m} / \mathrm{m}$ before and after exposure to gamma rays were examined by scanning electron microscopy (SEM), Fourier transform infrared spectroscopy (FTIR) and X-ray diffraction. The effect of gamma radiation is clearly seen in the samples irradiated at a dose of $25 \mathrm{kGy}$. The main alteration in the polymeric material after exposure at the radiation range was a decrease in the mechanical properties, alterations in the chemical structure of the blend with an increase in the carbonyl and vinyl indices and the appearance of new crystalline symmetry generating a crystalline domain not existing before in the blend.
\end{abstract}

Keywords: polyethylene; gamma radiation; starch.

\section{INTRODUCTION}

Currently the enormous amount of garbage generated by man, largely consisting of long-lasting synthetic polymers, represents serious environmental problems that could be disastrous for humanity. ${ }^{1}$

Interest in biodegradable polymers has been growing rapidly in recent years; it could become an alternative for the problems of current environmental pollution generated by plastic garbage. ${ }^{2,3}$

The importance of the study of low-density polyethylene (LDPE) biodegradable formulations is motivating much research in this area. ${ }^{4}$ Polyethylene is used in several applications owing to its excellent properties, such as elasticity and flexibility. However, it is a polymer that is not degraded easily in the environment. One of the viable alternatives to accelerate the biodegradation of LDPE is the addition of a natural polymer, such as starch, to guarantee its partial degradation. ${ }^{5}$

The development of materials composed of a mixture of starch and polymeric synthetics constitutes a solution for the reduction of plastic wastes. Preliminary studies show that the removal of the starch in the mixture polymer/polysaccharide alters the physical properties of the plastic, facilitating its physical disintegration in the environment and, consequently, its biodegradation. ${ }^{6}$ As many polymers present promising applications in the food packaging and medical industries, it is important to study the effects of gamma radiation, in order for it to be a method of sterilization of an international standard.

In most of the cases, the dose of radiation necessary to provoke significant changes in the properties of polymeric materials $(>15$ $\mathrm{kGy}$ ) is considerably smaller than that required to cause any alteration in metals, ceramics or glasses. ${ }^{7}$ The properties of the polymeric material can be drastically affected by ionizing radiation or high energy radiation. The effects of the gamma radiation in the properties of low density polyethylene have been investigated and undesirable alterations, mainly in the thermal and mechanical properties, were observed by the modification in the structure of the polymer for the scission and/or crosslink of the chain. ${ }^{8,9}$

This paper presents the results of studies into the effect of ionizing radiation in LDPE/modified starch blends $(80 / 20 \mathrm{~m} / \mathrm{m})$

*e-mail:gmvinhas@yahoo.com.br through a variety of techniques used to identify and quantify the behavior of blends, being mechanical properties; scanning electron microscopy (SEM); Fourier transformed infrared spectroscopy (FTIR) and X-ray diffraction.

\section{EXPERIMENTAL}

\section{Materials}

Low density polyethylene (LDPE), EB-853, with flow index $2.7 \mathrm{~g} / 10 \mathrm{~min}\left(190^{\circ} \mathrm{C} / 2.160 \mathrm{~kg}\right)$, was supplied by Braskem. The starch used was Foxhead ${ }^{\circledR}$ 5901, amphiprotic type, made up of $27 \%$ amylose and $73 \%$ amylopectin, supplied by Corn Products Brazil.

\section{Blend preparation}

The LDPE/modified starch blends, composition 80/20 w/w, were obtained by mixture and fusion of the components in the mixture chamber of a HAAKE rheometer, under the following conditions: $50 \mathrm{~g}$, temperature at $140{ }^{\circ} \mathrm{C}$, maximum torque $50 \mathrm{Nm}$, rotor velocity $50 \mathrm{rpm}$, and total mixture at $10 \mathrm{~min}$. A processed blend was triturated in a grinding rotor axis, and its films were obtained in an hydraulic press, with a thickness of $0.175 \pm 0.25 \mathrm{~mm}$, in the following conditions: force 8 ton, time compressed of $1 \mathrm{~min}$, plates temperatures at $140^{\circ} \mathrm{C}$ and mold with $400 \mathrm{~cm}^{2} .{ }^{10}$

\section{Exposure of the blends to gamma radiation}

The samples were irradiated in the Department of Nuclear Energy at the Federal University of Pernambuco-Brazil. The dosage used was of $25 \mathrm{kGy}$. A source of ${ }^{60} \mathrm{Co}$, Gammacell type with a rate of $10.925 \mathrm{kGy} / \mathrm{h}$, at room temperature.

\section{Mechanical properties}

The mechanical properties of the samples, before and after exposure to gamma radiation, were analyzed in three samples in an EMIC DL 500 MF Universal Testing Machine, observing the ASTM D 638, ${ }^{11}$ at a room temperature of approximately $23{ }^{\circ} \mathrm{C}$, without humidity control. Measurements were done using a $450 \mathrm{~mm} / \mathrm{min}$ crosshead speed. 
The measurements were conducted for each sample and the results were averaged to obtain a mean value of tensile strength and percentage elongation.

\section{Scanning electron microscopy (SEM)}

The surface photographed was the area of rupture, of the blend samples before and after exposure to gamma radiation. The sample was covered with a fine layer of gold using carbon ribbon as support. The microscope used was the JEOL JSM-6360 with increases of 100 and 250 times.

\section{Fourier transformed infrared spectroscopy (FTIR)}

The Fourier Transformed Infrared (FTIR) technique has been used extensively in the investigation of polymeric blends and the inquiry of modified polymeric films.

The FTIR spectra were measured with Brucker 1FS66 using the technique of tablets of $\mathrm{KBr}$. Samples of LDPE/modified starch blends were used before and after the exposure to gamma radiation. The FTIR range of the samples in study were in a region of $500-4000 \mathrm{~cm}^{-1}$.

\section{X-ray diffraction}

The X-ray diffraction of the samples of LDPE/modified starch blends $80 / 20 \mathrm{~m} / \mathrm{m}$, before and after the exposure to gamma radiation, was determined using an X-ray diffractometer (Siemens Model D5000 ) with a target reference of: pipe of $\mathrm{Cu}$, voltage: $40 \mathrm{kV}$, current: $40 \mathrm{~mA}$, diffraction angle $2 \theta^{\circ}: 5-40^{\circ}$, and scanning speed: $0.04^{\circ} 2 \theta / \mathrm{s}$.

\section{RESULTS AND DISCUSSION}

\section{Mechanical properties}

In general the mechanical properties of polymeric material present alterations when they are exposed to gamma radiation once the material degrades, and consequently, the chains suffer scission.

The mechanical properties of the LDPE/modified starch blends before and after the exposure to gamma radiation were determined and the results are presented in Table 1 and Figure 1. These show the curves of stress (MPa) in function of the strain (\%) of the LDPE/ modified starch blends before and after the exposure to gamma radiation.

Table 1. Mechanical properties of the polymeric blends before and after exposure to gamma radiation

\begin{tabular}{lcc}
\hline $\begin{array}{l}\text { LDPE/modified } \\
\text { starch blend }\end{array}$ & $\begin{array}{c}\text { Tensile } \\
\text { strength }(\mathrm{MPa})\end{array}$ & $\begin{array}{c}\text { Percentage } \\
\text { elongation }(\%)\end{array}$ \\
\hline $0 \mathrm{kGy}$ & $35.61 \pm 8.65$ & $14.43 \pm 1.42$ \\
$25 \mathrm{kGy}$ & $31.63 \pm 3.19$ & $9.36 \pm 1.27$ \\
\hline
\end{tabular}

After exposure of the blend to gamma radiation a decrease of around $11 \%$ is observed in the tensile strength resistance, which is evaluated by the weight applied to the polymer at the moment of rupture. The elongation in the rupture, that evaluates the capacity of stretching of the polymer, already presented a decrease of around $35 \%$ after the radiation.

The results found in this work had been concordant with the results of Gorna et al., ${ }^{12}$ where they had verified that samples of PCL exposure to gamma radiation at a dose of $25 \mathrm{kGy}$, had presented a reduction of $12 \%$ of the tension in the rupture.

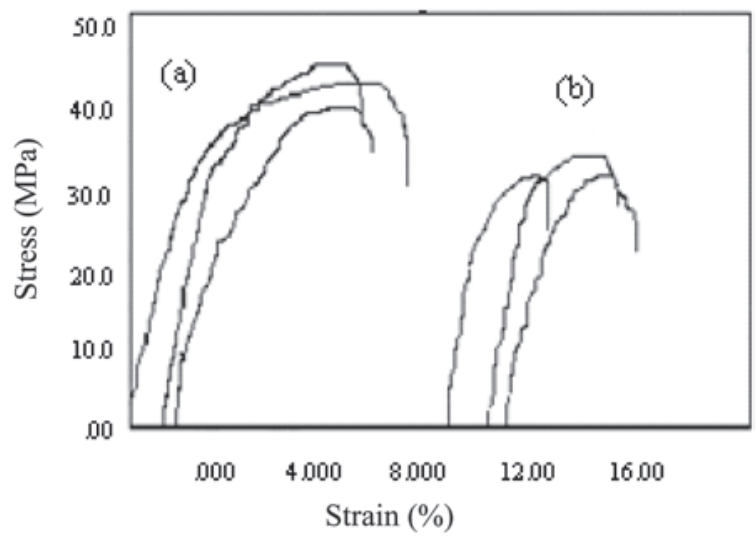

Figure 1. Stress-strain curves of LDPE/modified starch blends (a) after and (b) before exposure to gamma radiation at a dose of $25 \mathrm{kGy}$

Cataño et al. ${ }^{13}$ had verified in its work that the mechanical properties of the HDPE were influenced by gamma radiation, presenting reduction of $8.9 \%$ in the elongation in the rupture after exposition to gamma radiation at a dose of $25 \mathrm{kGy}$ which was attributed to crosslinking of amorphous region.

The tensile strength property in the rupture is related more to the damages caused by the radiation in the amorphous area of the material. ${ }^{14}$ However, it is the scissions in the linking molecules that cause the biggest loss of mechanical properties in a crystalline polymer. ${ }^{15}$

\section{Scanning electron microscopy (SEM)}

The SEM observations may be related to the mechanical properties of the LDPE/modified starch blend. The irradiation crosslinking of PE occurs preferentially in the amorphous sites. ${ }^{16-18}$ The oxidative degradation caused by gamma radiation in air is a diffusion-controlled process, ${ }^{19,20}$ therefore, it affects mainly the surface layers and the mechanical properties of irradiated polymer blend are expected to depend mainly on the matrix material. Additionally, the effects of gamma radiation damage on the fracture behavior of the polymer blend will depend on the loading rate. ${ }^{21}$ Scanning electron microscopy was used to check the changes on the surface of the fracture, of the studied LDPE/modified starch blends, before and after the exposure to gamma radiation at a dose of $25 \mathrm{kGy}$.

The scanning electron microscopy of the region of the fracture in the samples tested mechanically, allow the verification of modifications in polymeric blends.

Observing the microphotographs presented in Figure 2, verifies that the rupture of the samples, which had not been exposed to gamma radiation, occurred in ductile form. This is evident by the formation of fibrillas typical of a material that presents a certain elongation to break when submitted to force. However when the same material is exposed to gamma radiation it is evident that the fibrillas diminish, characterizing a less elastic material, presenting less elongation before breaching and therefore more fragility, shown in Figure 3.

The results of this work agree to the joined ones for Suarez and Mano, ${ }^{9}$ therefore the LDPE/modified starch blends after exposure to gamma radiation at a dose of $25 \mathrm{kGy}$, shows a brittle tensile behavior, characterized by elongation at break significantly lower than that of non-irradiated material. ${ }^{9}$

\section{Fourier transformed infrared spectroscopy (FTIR)}

The FTIR spectrums for the films in the study were obtained in the region of 500-4000 $\mathrm{cm}^{-1}$. The spectrum of FTIR of the LDPE/ 

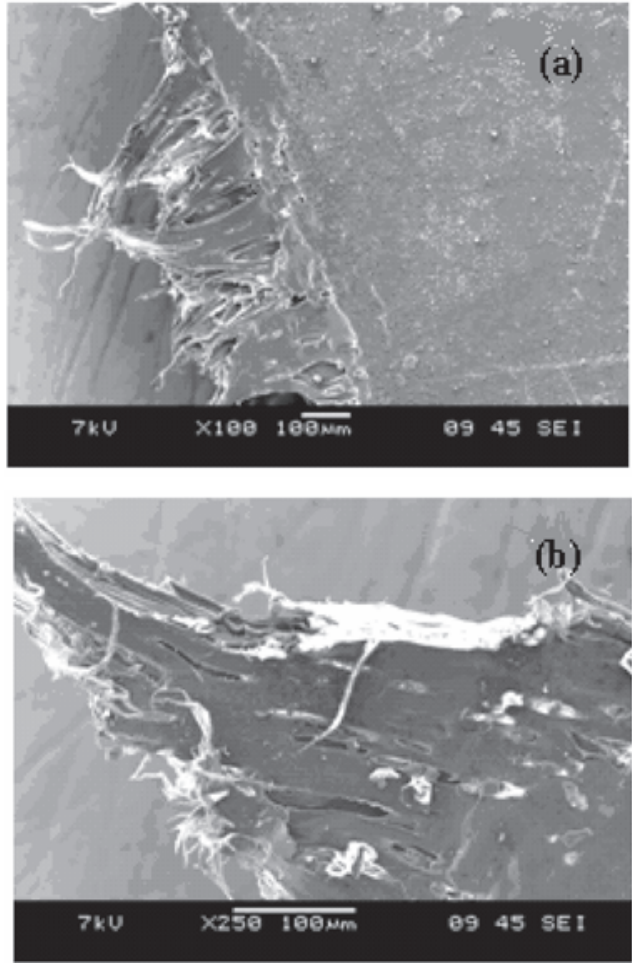

Figure 2. SEM microphotographs of fracture surfaces from the LDPE/modified starch blend before exposure to gamma radiation with increase of (a) $100 \mathrm{x} e$ (b) $250 x$
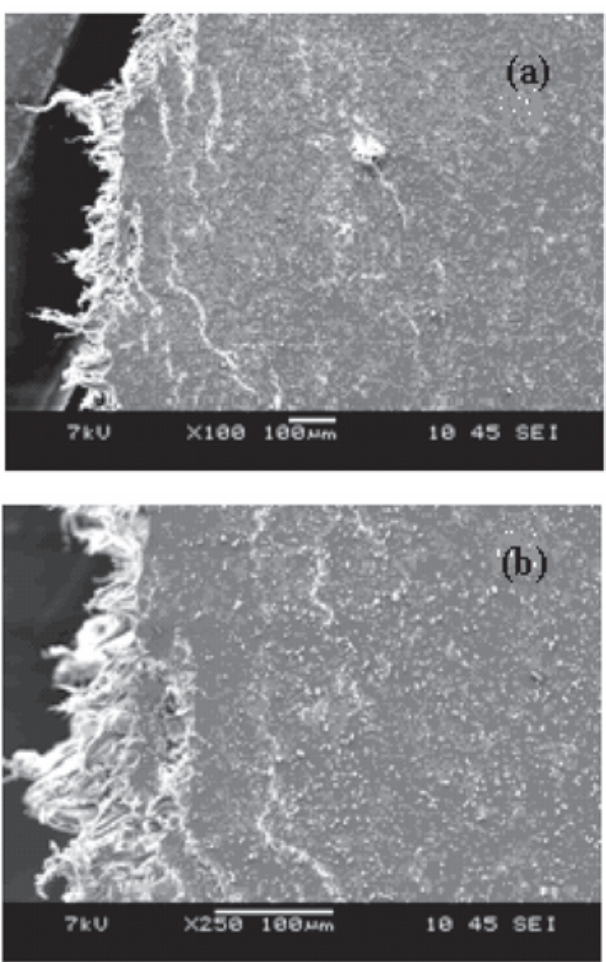

Figure 3. SEM microphotographs of fracture surfaces from the LDPE/modified starch blend after exposure to gamma radiation with increase of (a) $100 x \mathrm{e}$ (b) $250 x$

modified starch blends, before and after exposure to gamma radiation at a dosage of $25 \mathrm{kGy}$, presented differences due to the formation or change of new groups, as shown in Figures 4 and 5.

The changes in the bands at $1715-1740$ and $1620-1680 \mathrm{~cm}^{-1}$

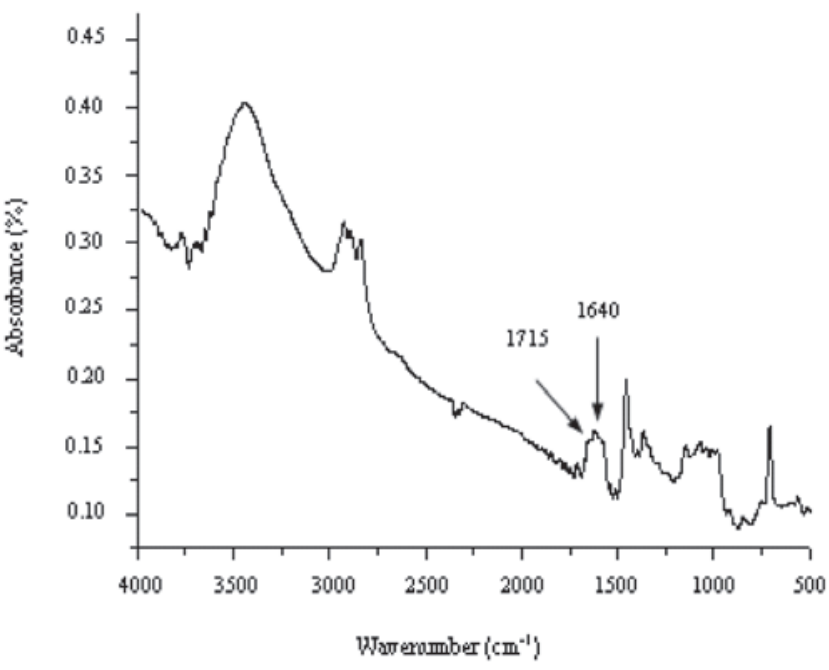

Figure 4. FTIR spectrum of LDPE/modified starch blends before exposure to gamma radiation

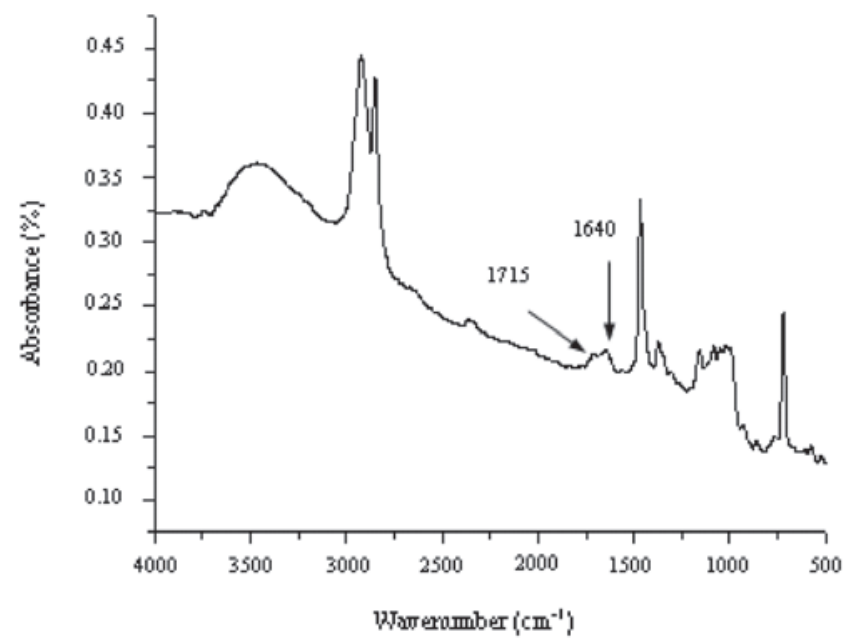

Figure 5. FTIR spectrum of LDPE/modified starch blends after exposure to gamma radiation

corresponding to the carbonyl $(\mathrm{C}=\mathrm{O})$ and vinyl groups $(\mathrm{C}=\mathrm{C})$, respectively, of non-irradiated and irradiated LDPE/modified starch blends, are due to the degradation process of blends.

The carbonyl index of the LDPE/modified starch blend before and after exposure to gamma radiation at a dose of $25 \mathrm{kGy}$, was calculated on the basis of the carbonyl band at $1715-1740 \mathrm{~cm}^{-1}$ and used the area of absorbance corresponding to the band at 2970 $\mathrm{cm}^{-1}$ (stretching $\mathrm{C}-\mathrm{H}$ ) as reference. The carbonyl index values obtained for LDPE/modified starch before and after exposure to gamma radiation were 10.26 and 35.51, respectively. Vinyl index was calculated on the basis of relative intensities of vinyl band at $1640 \mathrm{~cm}^{-1}$ and used the same reference peak. Values obtained were 19.23 and 28.98 for LDPE/modified starch blend before and after exposure to gamma radiation, respectively.

The irradiation of material with ionizing radiation, gamma radiation, leads to formation of reactive intermediates, free radicals, ions, and atoms in excited states. These intermediates can follow several reaction paths that result in rearrangements and/or the formation of new bonds. ${ }^{22}$ In this work occurred the increase of carbonyl and vinyl index. 


\section{X-ray diffraction}

The Figure 6 shows X-ray diffractograms of the LDPE/modified starch blend $80 / 20 \mathrm{~m} / \mathrm{m}$ before and after exposure to gamma radiation at a dose of $25 \mathrm{kGy}$. Comparing these diffractograms it can be verified that the formation of a new peak of diffraction exists, which indicates that radiation causes the formation of new crystalline symmetries.

The determination of the crystalline fraction or degree of crystallinity is an important parameter to define the physical and chemical properties of the polymeric material. The final degree of crystallinity in a polymer sample is dependent on the ability of chains to form crystals as well as the mobility of the chains during the crystallization process..$^{23}$ The degree of crystallinity, presented in Table 3, was calculated considering the area under the diffracted peaks, deducting of the amorphous halo, area not crystalline of polymer material, in accordance with Equation 1:

$$
\% C=\frac{I_{c}}{\left(I_{c}+K I_{a}\right)} \cdot 100
$$

where $\% C$ is crystalline fraction, $I_{c}$ is the result of the integration of the diffraction peaks, $I_{a}$ is a result of the integration of the amorphous halo, gotten through the Gaussiana approach of the diffractogram (Figure 6), and $K$ is a constant of characteristic proportionality of each polymer, in this case polyethylene, 1.23. ${ }^{24}$ The data referring to the subtraction of the amorphous halo was obtained by the Gaussiana approach (Table 2).

Table 2. Parameters of the calculation of crystallinity and crystalline fraction $(\% \mathrm{C})$ of polymeric blends before and after exposure to gamma radiation

\begin{tabular}{lccc}
\hline $\begin{array}{l}\text { LDPE/modified } \\
\text { starch blend }\end{array}$ & $\begin{array}{c}\text { Integral of } \\
\text { diffractogram }\end{array}$ & $\begin{array}{c}\text { Area } \\
\text { (Gaussiana approach) }\end{array}$ & $\% C$ \\
\hline $0 \mathrm{kGy}$ & 2586.99 & $1121.62 \pm 18.82$ & 65.21 \\
$25 \mathrm{kGy}$ & 2554.11 & $1045.86 \pm 18.55$ & 66.50 \\
\hline
\end{tabular}

The percentage of crystallinity presented an increase when the films were displayed to gamma radiation. This fact reinforces the hypothesis that the fragments of molecules in the amorphous region and linking molecules rearrange themselves on the crystallites, causing an increase in the degree of crystallinity of the polymer.

Luo and Netravali ${ }^{14}$ had observed the increase of the crystallinity of the PHB, induced for the gamma radiation. Their work had justified this increase by means of the phenomenon of the nucleation, where great crystalline orders are destroyed random by gamma radiation, having sprouting of small and innumerable crystallites.

\section{CONCLUSIONS}

The LDPE/modified starch blend 80/20 $\mathrm{m} / \mathrm{m}$, when exposed to gamma radiation at the dose of sterilization $(25 \mathrm{kGy})$, presented alterations in its mechanical properties, resulting in reductions of $11 \%$ in the tensile strength and of $35 \%$ in the percentage elongation. These results were confirmed by the SEM.

In addition, it was possible to evaluate alterations in the chemical structure of the blend by the increase of carbonyl and vinyl index when exposured to gamma radiation. The formation of these new functional groups in the structure of polymer is decurrent of the linking that are broken and new linking formed in the structure of polymer, reinforce the characterization of the degradation process
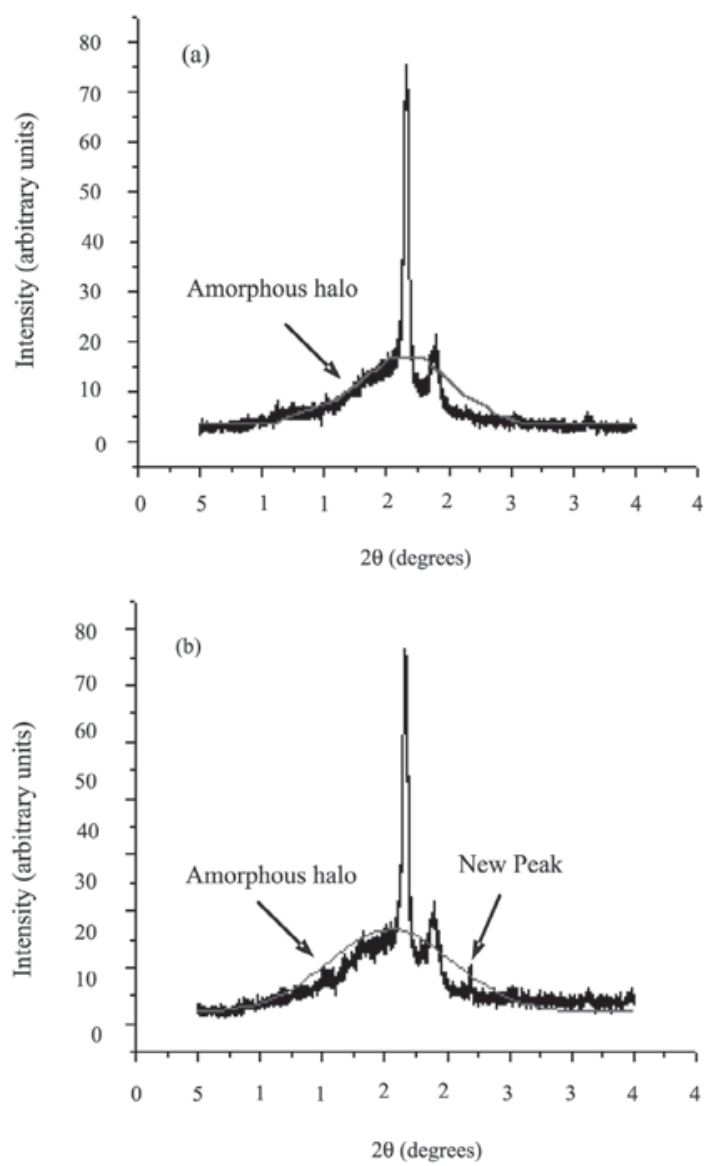

Figure 6. Gaussiana approach for the subtraction of the amorphous halo in the X-ray diffractograms of LDPE/modified starch blends $80 / 20 \mathrm{~m} / \mathrm{m}$ (a) before and (b) after exposure to gamma radiation at a dose of $25 \mathrm{kGy}$

of the polymeric material.

The gamma radiation also favored the appearance of new crystalline symmetry, generating crystalline areas previously nonexistent in the blend.

Although the LDPE/modified starch blend presented a reduction in the mechanical properties, the traction resistance was less emphasized after its exposure to gamma radiation. This indicates a very promising polymer for use in packaging materials, since its properties of a general form are not affected by the effect of radiation at the dose of sterilization, in comparison with other polymers such as PVC, pure LDPE and PP amongst others. In addition, this material still presents the advantage of being partially biodegradable, due to the presence of starch in its composition.

\section{ACKNOWLEDGEMENTS}

We would like to thank Dr. L. Hecker and Dr. S. M. de L. Silva (DEMA - Federal University of Campina Grande-Brazil) for allowing the use of their laboratory and equipment for the preparations of the blends, Braskem and Corn Products Brazil for supplying the LDPE and starch, respectively, and the Analytical Central of the Chemistry Department at the Federal University of Pernambuco-Brazil. We also gratefully acknowledge the financial support from CAPES, FACEPE and CNPq.

\section{REFERENCES}

1. Rosa, D. S.; Chui, Q. S. H.; Pantano Filho, R.; Agnelli, J. A. M.; Polímeros: Ciência e Tecnologia 2002, 12, 311. 
2. Pedroso, A. G.; Rosa, D. S.; Carbohydr. Polym. 2005, 59, 1.

3. Spinacé, M. A. S.; De Paoli, M. A.; Quim. Nova 2005, 28, 65.

4. Nakamura, E. M.; Cordi, L.; Almeida, G. S. G.; Duran, N.; Mei, L. H. I.; J. Mater. Chem. 2005, 162, 236.

5. Al-Ali, M.; Madi, N. K.; Al Thani, N. J.; El-Muraikhi, M.; Turos, A.; Vacuum 2003, 70, 227.

6. Chandra, R.; Rustgi, R.; Polym. Degrad. Stab. 1997, 56, 185.

7. Charlesby, A.; Radiation Chemistry of Polymeric Systems, Pergamon Press: New York, 1960.

8. Kacarevié-Popovié, Z.; Kotoski, D.; Stojanovic, Z.; Dakovic, V.; Polym. Degrad. Stab. 1997, 56, 227.

9. Suarez, J. C. M.; Mano, E. B.; Polym. Degrad. Stab. 2001, 72, 217.

10. Lima, S. M.; Dissertação de Mestrado, Universidade Federal de Pernambuco, Brasil, 2005.

11. ASTM Standard Annual Book, ASTM D638, 1982.

12. Gorna, K.; Gogolewski, S.; Polym. Degrad. Stab. 2003, 79, 465.

13. Cataño, L.; Albano, C.; Karam, A.; Domínguez, N.; Sánchez, Y.; González, J.; Nucl. Instrum. Methods Phys. Res., Sect. B 2005, 236, 348.
14. Luo, S.; Netravali, N.; J. Appl. Polym. Sci. 1999, 73, 1059.

15. Rabello, M. S.; White, J. R.; Polímeros: Ciência e Tecnologia 1997, 47, 56

16. De Vries, K. L.; Smith, R. H.; Fanconi, B. M.; Polymer 1980, 21, 949.

17. Bhateja, K.; Yarbrough, S. M.; Andrews, L. E.; J. Macromol. Sci., Part B. Phys. 1990, 29, 1.

18. Kostoski, D.; Kacarevié-Popovié, Z.; Novokovié, L. J.; Polym. Degrad. Stab. 1995, 50, 49.

19. Spadaro, G.; Eur. Polym. J. 1993, 29, 851.

20. Viksne, A.; Zicans, J.; Kalbis, V.; Bledzki, A. K.; Angew. Makromol. Chem. 1997, 249, 151.

21. Philips, D. C.; Burnay, S. G.; Polymers in the nuclear industry, Clegg DW: London, 1994.

22. Haji-Saeid, M.; Sampa, M. H. O.; Chmielewski, A. G.; Radiat. Phys. Chem 2007, 76, 1535

23. Rabello, M. S.; White, J. R.; Polym. Degrad. Stab. 1997, 56, 55.

24. Canevarolo Jr, S. V.; Técnicas de Caracterização de Polímeros, Artliber Editora Ltda: São Paulo, 2003. 